\title{
Acquired retraction syndrome after sixth nerve palsy
}

\author{
J. LAWTON SMITH AND MELVYN DAMAST* \\ From the Bascom Palmer Eye Institute, Department of Ophthalmology, University of Miami School \\ of Medicine, Miami, Florida, U.S.A.
}

Duane (1905) emphasized six features of a characteristic congenital ocular motility syndrome:

(r) Complete, or less often partial, loss of abduction of the affected eye;

(2) Partial, or rarely complete, restriction of adduction of the affected eye;

(3) Retraction of the affected eye into the orbit on adduction;

(4) Oblique overshoot of the affected eye either up and in or down and in on adduction;

(5) Partial closure of the lids (pseudo-ptosis) of the affected eye on adduction;

(6) Paresis of convergence, the affected eye remaining fixed in the primary position while the sound eye is converging.

This ocular motility pattern has since been known as Duane's retraction syndrome and is characteristically congenital. The purpose of this paper is to report the case of a patiend who developed the characteristic features of Duane's retraction syndrome after a posts traumatic ophthalmoplegia, and in whom photographic documentation exists to provô. that the defect did not previously exist.

\section{Case report}

A 57-year-old right-handed white male was first seen on May 10, 1970, by the courtesy of Dr. Meyerson, with a chief complaint of double vision. He had enjoyed good health until October, I968, when he developed classic tic douloureux in the left third trigeminal division. An alcohol injection was followed by good relief for 18 months. The pain then recurred and a repeat injection gave relief again for 5 months. The patient was then treated with Tegretol for 3 to 4 weeks with good relief, but this was stopped because of a drop in the leucocyte count.

Therefore, on August 21, 1970, a left trigeminal rhizotomy was performed. Postoperatively he had decreased sensation over the left side of the face, but also had ptosis of the left upper lid and double vision. The pain began to recur and accordingly on March 18, I971, a suboccipital craniotomy was performed with resection of the entire sensory root of the left fifth nerve. After this procedure, he at last became pain free. The only remaining complaint was diplopia, and because of this he was referred for neuro-ophthalmological consultation. The only position in which he could avoid diplopia was in extreme right gaze. There were no other neurological complaints.

\section{Examination}

The corrected visual acuity was $20 / 15^{-1}$ in both eyes. He wore an occluder over the left eye. There was total facial anaesthesia to all three trigeminal divisions on the left to light touch. The palpebral fissure was equivocally narrower on the left, but there was definite anisocoria. The right pupil measured $3 \mathrm{~mm}$. and the left $2 \mathrm{~mm}$. (Fig. $\mathrm{I}$ ). The right pupil reacted $3+$ to light and the left $\mathrm{i} \cdot 5+$. 


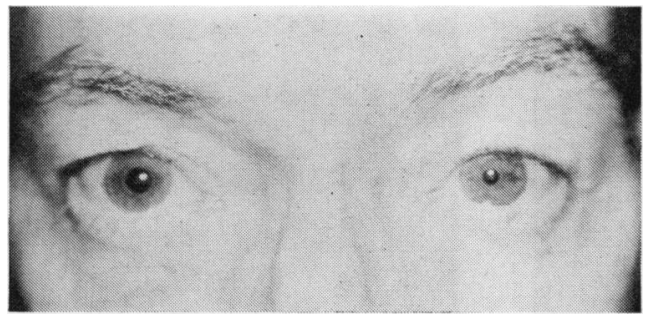

FIG. I Eyes in primary position on September 9, 1971. Note left Horner's syndrome

The most striking findings concerned the ocular motility. Adduction and abduction of the right eye were full in all directions. The left eye moved up and down fully, but left $1.5 \mathrm{~mm}$. of visible sclera on extreme adduction, and could not be adbucted beyond the midline. There was definite retraction of the left eye into the orbit on looking right, and the characteristic lid signs of Duane's retraction syndrome were present. When the patient looked down and to the right, the left palpebral fissure narrowed. When he attempted to look down and to the left, the left upper lid retracted and the fissure widened (Fig. 2).

(a)

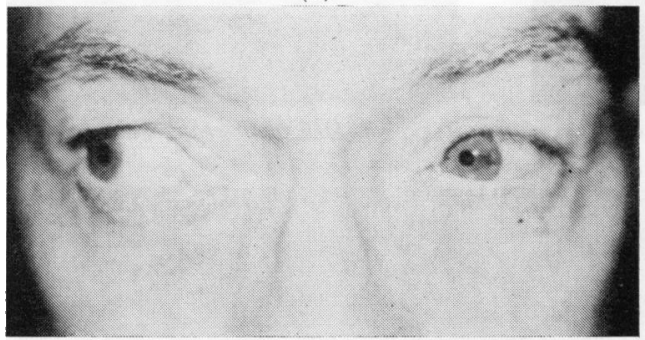

(c)

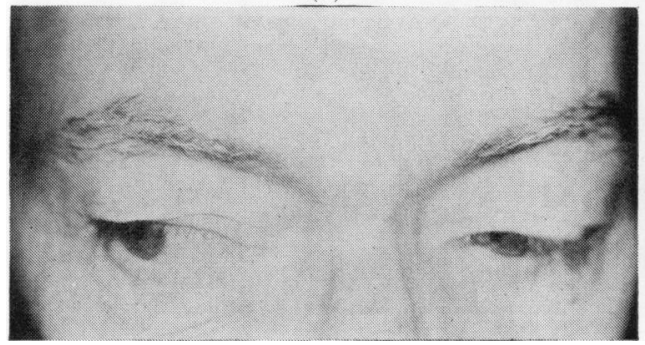

(b)

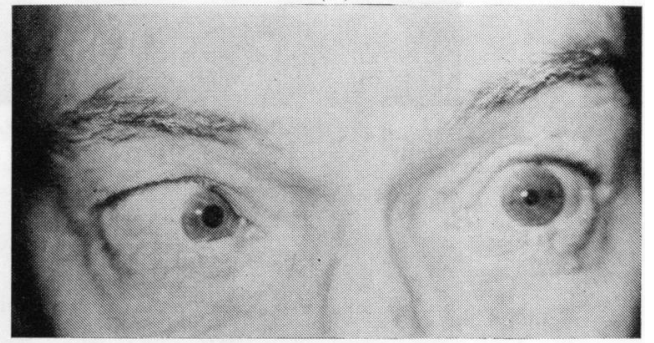

(d)

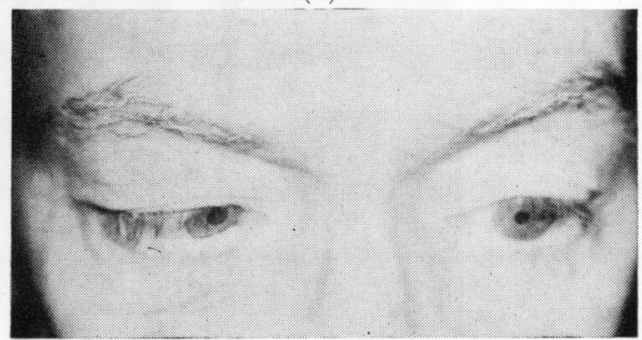

FIG. 2 Left sixth nerve palsy is seen in the upper left photograph on September 9, 1971. Note narrowing of left fissure on gaze down and right (lower right) and widening of left fissure on gaze down and left (lower left)

The optokinetic responses were of interest. With targets up or down, there was a $3+$-response in both eyes. With targets to the right, there was a $4+$ response in the right eye and a $\mathrm{I}+$ response in the left. Likewise, with targets to his left, the left eye had only a trace to $\mathrm{I}+$ response, while the right eye showed a normal $4+$ response.

The visual fields, slit-lamp examination, and ophthalmoscopic findings were all normal. A cocaine test was performed and was strikingly positive in that the right pupil dilated well to cocaine but the left did not. Applanation ocular tensions were $14 \mathrm{~mm}$. $\mathrm{Hg}$ on the right and 15 on the left. The impression was that of left sixth nerve palsy and Horner's syndrome after surgery for left third division tic douloureux, and acquired Duane's syndrome after a post-surgical ophthalmoplegia.

Old photographs showed the patient's eyes in the primary position, moderate right and left gaze, and full right and left gaze; all movements were full and normal (Figs 3 to 7 ). 


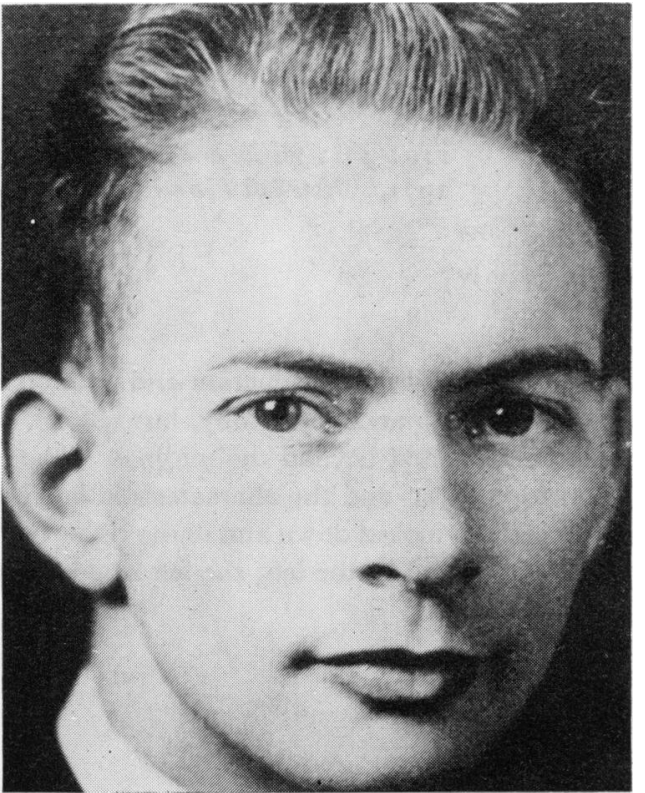

FIG. 3 Old photograph-eyes in moderate right gaze

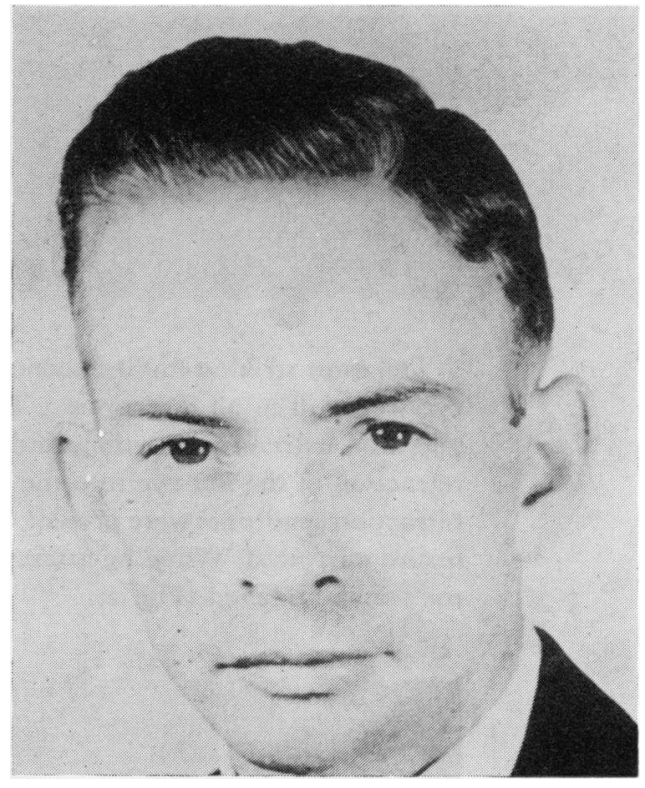

FIG. 4 Old photograph-eyes in moderate left gaze
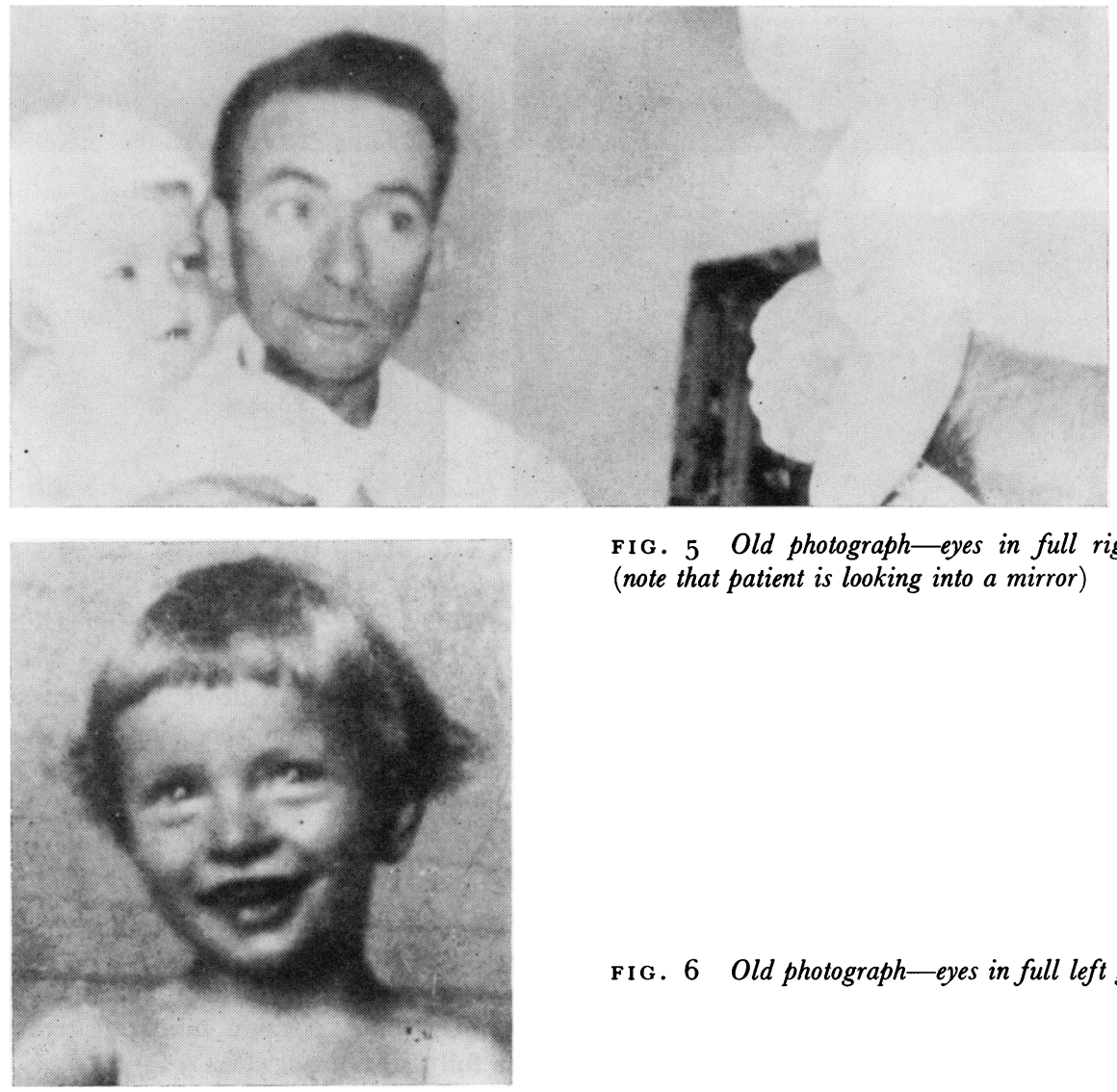

FIG. 5 Old photograph-eyes in full right gaze (note that patient is looking into a mirror)

FIG. 6 Old photograph-eyes in full left gaze 
Because of persistence of diplopia, the patient was operated on October I, I97I. Under anaesthesia, a careful forced duction test was performed. The left eye could be turned up and down normally. However, the test was positive in that there was definite resistance on attempting to turn the left eye either in or out. The left medial rectus was then recessed $3.5 \mathrm{~mm}$. and a Hummelsheim procedure was carried out by transplanting the temporal halves of the vertical recti to the lateral rectus insertion. Postoperatively, the patient had a position of single binocular vision just to the left and slightly below the primary position. He became able to abduct the left eye about $15^{\circ}$, and with a small prismatic correction in his spectacles had no diplopia straight ahead and was comfortable.

\section{Discussion}

A 57-year-old man developed left third division tic douloureux, and immediately after a trigeminal rhizotomy he was left with ptosis and double vision. Examination 9 months later revealed left sixth nerve palsy, left Horner's syndrome, and typical findings of Duane's retraction syndrome on the left. The globe retracted on adduction, and the fissure narrowed on adduction and widened on attempted adduction. The horizontal optokinetic responses were dissociated with poorer responses in the left eye to both right and left targets. A forced ductions test was positive in the left eye. Old photographs confirmed that the patient had had no eye trouble before the neurosurgical operation. He had also passed a pilot's physical examination for flying without any abnormality being observed about 18 months before the rhizotomy.

The pathogenesis of the acquired retraction syndrome in this patient is of great interest. It may be questioned whether there had been some concomitant trauma to the left third nerve at the time of the original surgical trauma. In favour of this was the fact that the operating surgeon stated that the ptosis was rather marked in the early postoperative period, and that this later improved, and that the left pupil reacted more sluggishly to light in a motor fashion than did the right. Against significant involvement of the left third nerve, however, were the following findings 9 months after the trauma:

(I) There was no vertical restriction of movement in the left eye;

(2) The left pupil was smaller than the right because of Horner's syndrome;

(3) The lid findings were the exact opposite of those seen in the syndrome of aberrant regeneration of the third nerve;

(4) The vertical optokinetic responses were equal in both eyes to both up and down targets.

The relationship between horizontal gaze and the palpebral fissures must be emphasized as being quite different in Duane's retraction syndrome and in aberrant regeneration of the oculomotor nerve. Thus, in the syndrome of misdirection-in-regeneration of the third nerve, the palpebral fissure characteristically narrows on abduction, but widens on adduction (Sturm and Smith, I965; Forster, Schatz, and Smith, 1969). Conversely, in Duane's syndrome, the palpebral fissure characteristically widens on abduction, but narrows on adduction. These findings are thus seen to be exactly the opposite. In the case here reported, the left palpebral fissure widened on attempted abduction, but narrowed on adduction. This is typical of Duane's syndrome and the opposite of aberrant regeneration of the third nerve. One cannot exclude the possibility that the left third nerve was concomitantly involved to some degree in this patient at the same time as the sixth nerve, sympathetics, and fifth nerve were involved, and this seems to be a plausible hypothesis.

Dr. Susac and Dr. Hoyt brought to our attention a report by Otradovec (1968) of the development of a bilateral retraction syndrome in a woman with bilateral sixth nerve palsies caused by a pontine glioma. To our knowledge, the case here reported is the only 
instance of a retraction syndrome following an acquired ophthalmoplegia in which the exact date and type of trauma are known. Thus, there is no question of orbital involvement in this patient as from a blow-out fracture of the orbital walls, for the onset of double vision was noted immediately after a transcranial approach to the left gasserian ganglion. The theoretical significance of this case in the pathogenesis of Duane's syndrome is obvious. If a retraction syndrome can follow surgical trauma to the peripheral cranial nerves, there is no reason to doubt that such a syndrome could follow a congenital trauma to the $\frac{\bar{\sigma}}{\bar{\omega}}$ same region.

\section{Summary}

A 57-year-old man had a left trigeminal rhizotomy for classic tic douloureux. Post- $\frac{\vec{\omega}}{\omega}$ operatively he had a left sixth nerve palsy and a Horner's syndrome and showed the classic findings of Duane's retraction syndrome on the left. Old photographs confirmed the fact that the defect had not previously existed. The theoretical application of this case of an acquired retraction pattern to our understanding of the pathogenesis of the typical congenital Duane's syndrome is evident.

\section{References}

DUANe, A. (1905) Arch. Ophthal., 34, I 33

fORSter, R. K., SGhATZ, N. J., and SMith, J. L. (1969) Amer. J. Ophthal., 67, 696

otradovec, J. (1968) Klin. Mbl. Augenheilk., 153, 686

sturm, r. J., and smith, J. L. (1965) Trans. Amer. Acad. Ophthal. Otolaryng., 69, 1054 